\title{
The Adoption of Robotic Process Automation Technology to Ensure Business Processes during the COVID-19 Pandemic
}

\author{
Julia Siderska
}

check for updates

Citation: Siderska, J. The Adoption of Robotic Process Automation Technology to Ensure Business Processes during the COVID-19 Pandemic. Sustainability 2021, 13, 8020. https://doi.org/10.3390/ su13148020

Academic Editor: Ewa Ziemba

Received: 5 July 2021

Accepted: 14 July 2021

Published: 18 July 2021

Publisher's Note: MDPI stays neutral with regard to jurisdictional claims in published maps and institutional affiliations.

Copyright: (C) 2021 by the author. Licensee MDPI, Basel, Switzerland. This article is an open access article distributed under the terms and conditions of the Creative Commons Attribution (CC BY) license (https:// creativecommons.org/licenses/by/ $4.0 /)$.
Faculty of Engineering Management, Bialystok University of Technology, Wiejska 45a Street, 15-351 Bialystok, Poland; j.siderska@pb.edu.pl

\begin{abstract}
The study provides knowledge on the adoption of the Robotic Process Automation (RPA) technology during the COVID-19 pandemic in 110 Polish service companies. As this research was the first of its kind in Poland, the objectives of the CAWI survey were to identify the technology features of the RPA technology and the related determinants and barriers influencing the adoption of the RPA as well as to determine correlations between them. Moreover, the statistical analyses involved considering whether there were differences in the evaluation of individual RPA technology features, mainly in terms of perceived usefulness, ease of use, security and functionality. The results of the study show that almost $60 \%$ of the respondents indicated that robotization tools allowed maintaining continuity of business processes during the pandemic. The highest rated were features related to usefulness of the RPA technology. Furthermore, the analysis pointed to the most frequently indicated barriers to technology implementation that were related to nonoptimized, nonstandardized and non-digitized processes with a large number of exceptions. The study contributes to scientific knowledge and has practical implications for process automation decision-makers concerned with the adoption of the Robotic Process Automation technology. The obtained results can help them to understand the potential drivers of and barriers to the adoption of software robots by enterprises and may be an important determinant for companies' managers in the field of implementing such solutions.
\end{abstract}

Keywords: Robotic Process Automation (RPA); business processes; software robots; business continuity

\section{Introduction}

The global COVID-19 pandemic disrupted the way all organizations currently operate. They have been forced to roll out their disaster recovery programs to stabilize and ensure their processes and operations. The coronavirus has shifted all industries to remote-first, as business processes have been replaced by online business operations [1], with sustainable business continuity becoming the most important priority. Business continuity is an organization's ability to ensure essential functions during and after a crisis, collapse, catastrophe, disaster, pandemic, etc. As a result of the coronavirus pandemic persisting globally since early 2020, enterprises and institutions have found themselves in a completely new reality and have experienced the need to face new management, organizational, technological and financial challenges. The necessity for remote work, pandemic shortages and the need to reduce operating costs have made innovative IT technologies supporting the maintenance of operational processes especially important and useful. In the current situation, it is vital to react forthwith in order to mitigate impacts and other risks [2-7].

The technologies driven by the IT sector play vital roles during the COVID-19 pandemic and they will also be crucial in the post-pandemic world, especially those which can reduce the workload for humans, manage the organization and ensure the continuity of the business [8]. The coronavirus pandemic has established the need for the adoption of emerging and future technologies in order to address the upcoming organizational, 
economic and management challenges. Technological advances are now accelerating faster than ever before to stay ahead of the consequences and acquire new capabilities [9]. Some authors attempt to study all emerging, future and disruptive technologies that can be utilized to mitigate the impact of the COVID-19 pandemic. The most often indicated technologies are, among others, artificial intelligence, robotics, big data, cloud computing, virtual reality and digital information technologies $[5,6]$. Nah and Siau discussed how information technology such as data analytics, artificial intelligence, machine learning, robotics, digital commerce and the Internet of things can be used to enhance resilience and continuity of business operations [10]. Automation has also arisen as an invaluable asset for organizations to embrace this changing way of work. Many authors emphasize that the world is witnessing the importance of automatization and robotization technologies and briefly summarize robotic applications during the current pandemic [11,12]. However, there is still a lack of detailed and systematic reviews of the robotic research for the pandemic from the technologies' perspective [13].

Robotic Process Automation is an emerging technology automating business processes and combines software, artificial intelligence and machine learning capabilities and algorithms to imitate the activity of human workers [14] and automate manual tasks within workflow and process-related applications and operations. Essentially, this technology enables repetitive, rule-based tasks to be shifted from people to software robots [15]. The RPA technology is a disruptive trend and one of the most cutting-edge digital transformation technologies which can be implemented by organizations to cut costs, save time, maximize resources via the automation of repetitive tasks [16] and ensure business continuity during unprecedented and unexpected crisis events. Moreover, it also helps to ensure that customer service levels are not compromised and business-as-usual operational efficiency is maintained.

The RPA technology enables increasing competitiveness, reducing costs and thus improving financial results. Above all, such solutions allow increasing the efficiency of processes by creating new, sustainable practices, including, for example, digitization and automation of individual operational activities and entire processes at an enterprise. This issue may be of particular importance in the face of the ongoing pandemic and future unforeseen events.

Since RPA is considered a useful technology, the features of such a solution as well as the determinants of and barriers to the adoption of RPA during the pandemic should be identified. The conclusions established on the basis of the recent literature analysis allow formulating the research gap. There is a need in conducting quantitative analyses of the effects of RPA and more research on drivers for RPA adoption. In response to this research gap, the author considers in this paper the technology features influencing the adoption of RPA to ensure proper business processes during the COVID-19 pandemic.

The study aimed to identify the most significant features that influence the adoption of the RPA technology by Polish service enterprises. Such information could be of practical value for managers not only during the COVID-19 pandemic, but also in case of any unprecedented crisis situations as well as in the face of an increasingly rapid digital transformation. The following detailed research objectives were formulated:

1. Diagnosis of the impact of the ongoing COVID-19 pandemic on companies' operations.

2. Identification of the key features that influence the adoption of the RPA technology during the pandemic in the opinion of representatives of Polish service companies.

3. Identification of the key determinants and barriers contributing to the adoption of RPA during the pandemic and the analysis of their importance.

4. Determination of differences in the evaluation of the RPA technology in terms of usefulness, ease of use, security and functionality.

5. Estimation of correlations between the determinants of implementing the RPA technology and the evaluation of the RPA technology. 
6. The calculation of regression coefficients for the RPA technology implementation determinants.

The contribution of this study is manifold. The conducted literature review allowed indicating important features of this technology. The author classified them taking into account their perceived usefulness, ease of use, security and functionality. The paper also provides knowledge on the adoption of the RPA technology during the COVID-19 pandemic to ensure that business processes can weather any staff shortages (workers taking sick leave, being quarantined at home or being indefinitely locked out from offices). The author identified the key features influencing the adoption of the RPA technology as well as the main barriers hindering the decision to implement such solutions. The study also makes a contribution by means of identifying differences in the evaluation of individual RPA technology features, mainly in terms of perceived usefulness, ease of use, security and functionality. In this regard, some practical recommendations can be formulated for managers of service companies who consider the adoption of such solutions in the future.

The remainder of the article consists of the following sections: Section 2 presents the literature review; Section 3 presents the methodology of the research process; in the next section, the results of the conducted survey are described and discussed; finally, the author formulates conclusions and presents limitations of the research as well as suggests potential directions for future research.

\section{Literature Review}

At the beginning of the digital transformation era, all attempts were mainly directed towards providing the highest quality of customer service. Currently, increasing attention is drawn to the digitization of operational and business processes, and the concept of digitization itself also covers service enterprises, including primarily such industries as finance, banking, insurance, marketing, accounting, public administration, logistics, etc. [14-19].

In terms of defining RPA, no consensus in the examined literature was identified. Most authors emphasize that Robotic Process Automation is an emerging approach that automates repetitive human tasks using robots [20]. Van der Aalst et al. [14] define RPA as an umbrella term for tools that operate with user interfaces in the same way as humans. A little different approach to defining Robotic Process Automation was adopted by the IEEE Corporate Advisory Group which defines RPA as the use of a "preconfigured software instance that uses business rules and predefined activity choreography to complete the autonomous execution of a combination of processes, activities, transactions, and tasks in one or more unrelated software systems to deliver a result or service with human exception management" [21].

\subsection{The Impact of the COVID-19 Pandemic on the Companies' Condition}

In the literature, one can identify publications presenting the possibilities of adopting IT solutions for sustainable business continuity management [22-27]. Some authors also consider the current pandemic and lockdown period and offer reflection on how the pandemic revealed the fragility of digitally immature organizations, education, work and life [28-31].

Automated software robots are increasingly adopted in many areas, such as human resources [32], IT [33], finance, insurance [34], telecommunication [35], education [36], banking [37], legal services [38], real estate management and logistics [39].

Providers of business process automation solutions are of the opinion that the most important issues threatening business continuity are connectivity and security as they can potentially restrict access to important information and business systems. Companies are turning towards technologies such as Robotic Process Automation to keep business and service levels afloat [40]. The research conducted by the author proved, however, that usefulness and perceived ease of use determine the most the adoption of RPA solutions by enterprises. 
The RPA technology enables increasing the competitiveness of enterprises, reducing costs and thus improving financial results. However, above all, these solutions allow increasing the efficiency of processes by creating new, sustainable practices, including, for example, digitization and automation of individual operational activities and entire processes at an enterprise. This issue may be of particular importance in the face of the ongoing pandemic and future unforeseen events. RPA can be the enabler of business continuity at a time when the world observes a potential disruption in the available workforce. To maintain sustainable business continuity amid the pandemic, organizations are using automation to support remote employee and service delivery.

Due to the outbreak of the COVID-19 pandemic, performing even the most businesscritical tasks has become crucial and burdensome. In this outbreak, the transformation and adoption of electronic content management have become a necessity for organizations. In order to meet the challenges posed by the prolonged coronavirus pandemic, many companies have decided to implement modern IT solutions and innovative technologies to support sustainable maintenance of business processes and ensure safety of their employees. Automation and robotics have arisen as crucial assets for organizations to embrace this changing way of work, i.e., to support remote working style, deliver services, increase operational efficiency and productivity and, what is crucial for the purpose of this paper, manage the organization and continuity of the business [1,41-47].

Despite the negative consequences of the global pandemic situation, there have been at the same time some positive technological advances. It should be stressed that mainly AI and RPA have recently experienced their zenit [48]. As a result of the difficulties brought by the COVID-19 pandemic, many companies have turned to robots in order to overcome the challenges of the pandemic. Compared with traditional human labor, robotic and autonomous systems have many advantages [4]. Robots can function as workers or assistants to help maintain social distancing restrictions [10]. Therefore, there is an extensive scope for customizing robots to undertake hazardous and repetitive jobs with precision and reliability [7].

\subsection{The Key Features of the RPA Technology}

For business processes, RPA refers to configuring software-based robots to do the work previously done by employees of the organizations. For example, such bots are able to make calculations, open and move files, parse emails, log into programs, connect to APIs, issue invoices, search databases, copy-paste, scrape web data, formulate the content of messages and extract unstructured data [17,18,20,49].

Many authors indicate strengths and weaknesses of RPA. However, the reviewed literature reveals a predominantly positive rating of the technology as its strengths outweigh weaknesses [50]. Software robots offer many benefits including improved business efficiency, increased productivity, data security, reduced cycle time and improved accuracy while allowing organizations to relieve their employees from repetitive and tedious tasks [51]. RPA promises to improve process performance, efficiency, scalability, auditability, security and compliance while at the same time being easy to implement at a relatively low cost compared to the traditional process automation [34,52-54].

RPA is often discussed and described in the literature as a gateway technology to artificial intelligence. Dialani [55] found that Robotic Process Automation as "the subset of AI that empowers IT groups to configure software 'robots' to capture data and perform routine tasks, is picking up traction as an alluring spot to start with outcomes centered AI implementation. RPA is getting one of the most exciting opportunities in the AI space and will keep on sparkling in 2020." RPA supported by modern technologies will become more comprehensive and all-embracing. Software, which is integrated with such technologies as machine learning, artificial (cognitive) intelligence, natural language processing and data analytics, can analyze and process data available in real time. The industries will be assisted by RPA to streamline business processes all the time and optimize operational efficiency. RPA allows an intelligent agent to eliminate operational errors and mimic manual routine 
decisions, including rule-based, well-structured and repetitive decisions, while AI has the cognitive capabilities to emulate the actions of human behavior [56]. RPA evolves into a form of cognitive automation. Through AI technologies, future software robots will no longer be rule-based but will draw on the experience of the already designed solutions [41].

The RPA technology is drawing more and more corporate attention within digital transformation that is rapidly developing and continuously progressing [16]. However, empirical research in the area of robotization of business processes is still in its infancy and calls for in-depth exploration. Insufficient literature is available on Robotic Process Automation as a niche and nascent field [18,41-46,50]. Although RPA is an emerging and promising technology, scientific research is almost absent. The academic research mainly lacks a theoretical and comprehensive analysis of such an approach [16]. Responding to the call by van der Aalst, academic discourse on RPA should also be initiated [14].

\subsection{The Determinants and Barriers of RPA Technology Adoption}

Despite the novelty of the coronavirus pandemic situation, the need for organizations to undergo major changes has been extensively considered in the well-established literature on organizational change management [42]. Regarding future research trends, Wang and Wang indicated particular technologies to enhance robotics research in the intra- and postpandemic era. They prioritized Robotic Process Automation together with AI, big data and cloud technologies, especially after the COVID-19 pandemic [13,57]. The authors reviewed more than 280 recent papers with a focus on robotic technologies during the pandemic, excluding the work focusing on medical research. The aim of the analysis was to identify the current influential technologies and technology trends in the future. With the use of text mining techniques, the authors classified the keywords indicated in the considered papers into several clusters regarding the most often appearing and cooccurring. One such cluster presenting strong interconnections with the "COVID-19" statement refers to Industry 4.0, digitalization, automation and robots. That means that those words have been mentioned many times by authors to strengthen the possibilities to utilize robotic applications during the pandemic [13].

Since RPA is considered to be an emerging and useful technology, the features of such a solution as well as the determinants of and barriers to the adoption of RPA during the pandemic should be identified. This is in line with a call for a more quantitative analysis of the effects of RPA [58]. Syed calls for more research on drivers for RPA adoption [46]. A more profound empirical analysis of the perceived benefits of RPA for public and private organizations should thus be carried out. In 2020, the pandemic was the single most important topic in news articles on RPA. However, scientific research seems to be lagging behind, with an insufficient number of articles discussing the supporting organizational role of RPA on the current COVID-19 pandemic [49]. Wewerka claims that the lack of empirical evidence confirming RPA effects necessitates studies for quantifying these effects [59]. The author points out the necessity to understand the variables of RPA adoption and use. Juntunen suggests investigating factors that influence the RPA adoption process and causalities between the key beliefs that influence the adoption process and the innovation, organizational, individual and management variables [60]. In effect, the adoption of new technologies calls for the examination of the features that could facilitate their proper and effective adoption and use. Vu and Lim examined the factors influencing the public attitude towards the use of AI/robots [61]. Robots call for the determination of innovative and creative ways to make use of technology in order to ultimately achieve a sustainable advantage [62]. Kumar and Ayedee proposed exploring the problems of SMEs during the COVID-19 pandemic and provide a solution to SMEs' problems in the form of technology adoption [63]. While the literature contains many "points of advice on" and "considerations for" RPA, it lacks a clear framework on what the critical success (or failure) features are and how they may have different implications. These may be considered as diverse organizational or process/task contexts in which RPA is analyzed. A deeper understanding 
of RPA's critical success features can help to identify and better manage different elements to gain the best outcomes from RPA [46].

The conclusions established on the basis of the recent literature analysis allow formulating the research gap. There is a necessity to conduct quantitative analyses of the effects of RPA and more research on drivers for RPA adoption. In response to this research gap, the author considers in this paper the technology features influencing the adoption of RPA solutions to ensure proper business processes during the COVID-19 pandemic.

\section{Research Methods}

In order to achieve the research goals, a sequence of logically following activities was designed. The research process of this study consisted of the following steps (Figure 1):

Step 1. Literature review in the field of business process automation with the use of the RPA technology

* Identification of the features of the RPA technology.

* Classification of the identified features of software robots into four groups of factors related to their functionality, perceived ease of use, perceived usefulness and security.

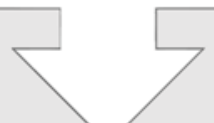

Step. 2. Development of the research tool (electronic questionnaire)

Step. 3. Selection of the research sample

Step 4. Quantitative CAWI research in 110 Polish service enterprises

Step 5. Analysis of the obtained results

Step. 6. Formulation of conclusions

Figure 1. Steps of the research process.

Step 1 was a literature review in the field of recent business processes automation and the possibilities of robotizing them with the use of software robots. The review was carried out mainly on the basis of the content of two scientific databases, namely Web of Science and Scopus. On the basis of the conducted literature review, the author identified a set of 22 features characterizing software robots. For the purpose of quantitative research, they were classified into four general groups related to their functionality (seven features), perceived ease of use (six features), perceived usefulness (five features) and security (five features). They are presented in Table 2.

Step 2 included the development of the research questionnaire. It consisted of three main parts. The first one contained questions that allowed diagnosing the state of business processes robotization at enterprises, but these results were not analyzed in this article. The next batch of the questions concerned the condition of enterprises and the state of robotization of processes during the COVID-19 pandemic. The respondents also indicated the processes that are supported with the use of RPA tools during the pandemic. Using the five-point Likert scale, the respondents also evaluated the determinants and barriers to the adaptation of RPA solutions during the pandemic and assessed features related to 
the usefulness, ease of use, functionality and security of this technology. The third and last part of the form contained questions about the intentions of companies regarding the implementation of the RPA technology in the future. The computer-assisted web interview (CAWI) technique was used to conduct a diagnostic survey and collect quantitative data with the main objective of identifying the features affecting the adoption of the RPA technology and the core expectations from the technology in this field.

The author chose deliberate sampling (Step 3) as the RPA technology is still emerging in Poland and not many enterprises have implemented such solutions and it is actually impossible to determine the population. The reason for the involvement of the purposive sampling was, ipso facto, the difficulty in identifying enterprises that adopted software robots strictly to ensure their business continuity during the COVID-19 pandemic.

The next step (Step 4) of the research process involved surveying the representatives of Polish service enterprises. The research was conducted among 110 representatives of Polish banks, financial and insurance institutions, media, utilities units and e-commerce enterprises. The survey was directed to the management staff, mainly chief technology officers, chief information officers, chief operating officers, heads of back offices, security, financial and sales departments as well as other employees responsible for technology and development of enterprises operating in the service sector. Figure 2 depicts the distribution of the service companies by business profile.

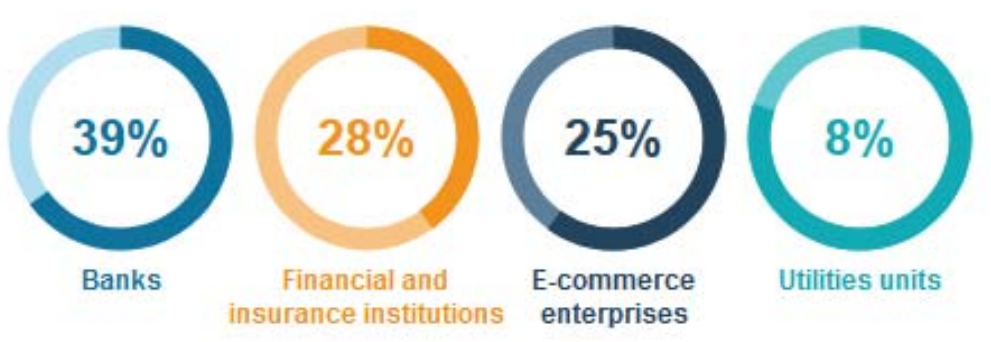

Figure 2. Distribution of surveyed companies by business profile.

In order to answer the research questions (Step 5), statistical analyses were performed using the IBM SPSS Statistics package (v. 26) which formed a basis for an analysis of basic descriptive statistics, a repeated measures ANOVA, an analysis of the Pearson correlation coefficient and a linear regression analysis. The classical threshold of $\alpha=0.05$ was taken as the level of statistical significance. The last step of the research process (Step 6) was the formulation of conclusions.

\section{Results and Discussion}

\subsection{The Impact of the COVID-19 Pandemic on the Companies' Condition}

The respondents were asked to indicate the impact of the ongoing COVID-19 pandemic on the companies' condition and operations (they could choose several answers).

The results show that half of the surveyed companies implemented new solutions in the field of robotization of business processes. Moreover, almost $60 \%$ of the respondents indicated that robotization tools allowed maintaining the continuity of business processes. It is also worth underlining that with the use of such solutions, nearly half of them were able to handle more orders and transactions. Representatives of 20 enterprises identified during the COVID-19 pandemic new business processes that could be automated or robotized. It should also be stressed that only a quarter of the respondents are of the opinion that the situation does not affect the condition of the enterprise and the activity is conducted in the same way as before. At the same time, almost $20 \%$ of them claim that they do not invest; the most important priority is to ensure sustainable business continuity and disaster recovery area (Table 1 ). 
Table 1. The impact of the COVID-19 pandemic on the companies' condition.

\begin{tabular}{|c|c|c|}
\hline Answer & $\%$ & Freq. \\
\hline The company's condition has deteriorated-fewer orders/we handle fewer transactions & 31.8 & 35 \\
\hline We do not invest; the most important priority is now the business continuity/disaster recovery area & 18.2 & 20 \\
\hline We lowered salaries of the employees, but have kept all the jobs & 0.0 & 0 \\
\hline Due to the lower number of orders/transactions, we had to lay off some employees & 9.1 & 10 \\
\hline The situation does not affect the condition of the enterprise; the activity is conducted in the same way as before & 27.3 & 30 \\
\hline The company's condition is improving; we handle more transactions & 13.6 & 15 \\
\hline We have implemented new solutions in the field of robotization of business processes & 50.0 & 55 \\
\hline Thanks to the use of robotization tools, we are able to maintain the continuity of business processes & 59.1 & 65 \\
\hline Thanks to the use of business process robotization tools, we are able to handle more orders/transactions & 46.6 & 51 \\
\hline We have identified new processes that can be automated/robotized & 18.2 & 20 \\
\hline We have migrated some of the processes to the environment and cloud systems & 9.1 & 10 \\
\hline
\end{tabular}

\subsection{The Key Features of the RPA Technology}

The respondents evaluated 22 features of the RPA technology included by the author to the following groups: usefulness, ease of use, security and functionality of the RPA technology, by indicating to what extent they agreed with the statements (1-strongly disagree, 5-strongly agree). The results of their assessments are presented in Table 2.

Table 2. Statistical measures of the evaluated features.

\begin{tabular}{|c|c|c|c|c|}
\hline Abbr. & Features & Average & $\begin{array}{l}\text { Standard } \\
\text { Deviation }\end{array}$ & $\begin{array}{l}\text { Coefficient of } \\
\text { Variation }\end{array}$ \\
\hline \multicolumn{5}{|c|}{ Usefulness } \\
\hline U1 & Robots can work a few times faster than employees $[45,46]$ & 4.24 & 0.9 & $21 \%$ \\
\hline $\mathrm{U} 2$ & $\begin{array}{l}\text { Robot-assisted workers can handle more processes, so they are more } \\
\text { productive and commit less mistakes [64] }\end{array}$ & 4.41 & 0.87 & $20 \%$ \\
\hline U3 & Robots can work $24 / 7$ almost completely unsupervised $[45,64]$ & 4.06 & 1.25 & $31 \%$ \\
\hline $\mathrm{U} 4$ & Robots make it possible to achieve economic benefits $[14,45]$ & 4.53 & 0.72 & $16 \%$ \\
\hline U5 & $\begin{array}{l}\text { Robots optimize the labor costs of back office employees and } \\
\text { increase the efficiency of the services provided }[65,66]\end{array}$ & 4.47 & 0.72 & $16 \%$ \\
\hline & Average & 4.34 & 0.89 & $21 \%$ \\
\hline \multicolumn{5}{|c|}{ Ease of use } \\
\hline E1 & $\begin{array}{l}\text { Robots replace employees in routine activities, leaving them with } \\
\text { creative and competent activities and handling of exceptions }[44,67]\end{array}$ & 4.71 & 0.59 & $12 \%$ \\
\hline E2 & Robots also operate on outdated technologies [68] & 4.18 & 0.88 & $21 \%$ \\
\hline E3 & $\begin{array}{l}\text { Robots do not require the use of additional integration technologies } \\
\text { (e.g., API, BPM) }[8,45,49]\end{array}$ & 3.76 & 1.25 & $33 \%$ \\
\hline $\mathrm{E} 4$ & Robots can be replicated easily [49] & 4.29 & 0.69 & $16 \%$ \\
\hline E5 & Robots can be implemented quickly [46] & 3.94 & 1.39 & $35 \%$ \\
\hline E6 & Robots do not require modification of IT systems and processes [67] & 3.71 & 1.31 & $35 \%$ \\
\hline & Average & 4.10 & 1.02 & $25 \%$ \\
\hline \multicolumn{5}{|c|}{ Functionality } \\
\hline $\mathrm{F} 1$ & $\begin{array}{c}\text { Robots are a way of introducing artificial intelligence into an } \\
\text { enterprise }[64,67]\end{array}$ & 3.65 & 1.27 & $35 \%$ \\
\hline
\end{tabular}


Table 2. Cont.

\begin{tabular}{|c|c|c|c|c|}
\hline Abbr. & Features & Average & $\begin{array}{l}\text { Standard } \\
\text { Deviation }\end{array}$ & $\begin{array}{l}\text { Coefficient of } \\
\text { Variation }\end{array}$ \\
\hline $\mathrm{F} 2$ & $\begin{array}{l}\text { It is possible to remotely, centrally manage all the implemented } \\
\text { robots [68] }\end{array}$ & 4.29 & 1.1 & $26 \%$ \\
\hline F3 & $\begin{array}{l}\text { Robots allow becoming independent from the historical knowledge } \\
\text { of the key employees [16] }\end{array}$ & 4 & 1.17 & $29 \%$ \\
\hline $\mathrm{F} 4$ & $\begin{array}{l}\text { Robots give the possibility of a smooth transition to any solutions } \\
\text { from other vendors [42] }\end{array}$ & 3.88 & 0.93 & $24 \%$ \\
\hline F5 & Robots can integrate legacy systems $[8,17]$ & 4.06 & 1.03 & $25 \%$ \\
\hline F6 & Robots can accelerate the digital transformation of an enterprise [16] & 4.18 & 0.81 & $19 \%$ \\
\hline \multirow[t]{3}{*}{ F7 } & $\begin{array}{l}\text { Robots can be implemented in companies with technological debt } \\
\text { [67] }\end{array}$ & 3.47 & 1.01 & $29 \%$ \\
\hline & Average & 3.93 & 1.05 & $27 \%$ \\
\hline & Security & & & \\
\hline S1 & Robots are practically failure-free [17] & 3.65 & 1.11 & $31 \%$ \\
\hline $\mathrm{S} 2$ & Robots help reduce human errors [64] & 4.24 & 0.9 & $21 \%$ \\
\hline S3 & $\begin{array}{l}\text { Robots do not cause the risk of data leakage; they maintain data } \\
\text { confidentiality [42] }\end{array}$ & 4 & 1.06 & $27 \%$ \\
\hline S4 & Robots enable the security of remote work [42] & 4.06 & 1.29 & $27 \%$ \\
\hline \multirow[t]{2}{*}{ S5 } & Robots maintain consistent performance [17] & 4.06 & 1.29 & $27 \%$ \\
\hline & Average & 4.00 & 1.13 & $27 \%$ \\
\hline
\end{tabular}

The mean value calculated for all the features in each group equaled 4.34 (usefulness), 4.10 (ease of use), 4.0 (security) and 3.93 (functionality) evaluated on a five-point Likert scale. This indicates that the features related to the usefulness of the RPA technology largely determine the decision of enterprises to adapt such solutions. The coefficient of variation indicates that the opinions of respondents varied insignificantly only in few cases (12-16\% on average). For almost all the features, the opinions of respondents were quite dispersed (from 20 to $35 \%$ ). Out of all the 22 features identified by the author, the highest scores on the five-point Likert scale (1-strongly disagree, 5 - strongly agree) were assigned to the following features of software robots: E1-Robots replace employees in routine activities, leaving them with creative and competent activities and handling of exceptions (4.71), U4-Robots make it possible to achieve economic benefits (453), U5Robots optimize the labor costs of back office employees and increase the efficiency of the services provided (4.47), U2-Robot-assisted workers can handle more processes, so they are more productive and commit less mistakes (4.41), E4-Robots can be replicated easily (4.29), F2-It is possible to remotely, centrally manage all the implemented robots (4.29), U1-Robots can work a few times faster than employees (4.24) and S2-Robots help reduce human errors (4.24). The average value of importance of all the features was 4.09. The lowest levels of importance (below the average value) were given to the following features of software robots: F7-Robots can be implemented in companies with technological debt (3.47), F1-Robots are a way of introducing artificial intelligence into an enterprise (3.65), S1-Robots are practically failure-free (3.65), E6-Robots do not require modification of IT systems and processes (3.71), E3-Robots do not require the use of additional integration technologies (e.g., API, BPM) (3.76), F4-Robots give the possibility of a smooth transition to any solutions from other vendors (3.88), E5-Robots can be implemented quickly (3.94).

The next step of the statistical analyses involved checking whether there were differences in the evaluation of individual RPA technology features. For this purpose, a repeated measures ANOVA was performed. The assumption of sphericity was broken: $\chi^{2}(5)=69.49$; $p<0.001$; hence, the Greenhouse-Geisser correction was used $(\varepsilon=0.73)$. 
The results of the analysis are statistically significant: $F(2.18,189.60)=12.25 ; p<0.001$; $\eta^{2} p=0.12$, which means that there is a statistically significant difference between these four groups of features, therefore post hoc tests had to be performed to check between which of them such statistically significant differences were observed. To investigate the exact differences between the features, Sidak's post hoc tests were performed (Table 3). It turns out that there are statistically significant differences between usefulness and ease of use, security and functionality. The other groups of features do not differ from each other.

Table 3. Post hoc test significance values for the RPA technology features' evaluation.

\begin{tabular}{cccc}
\hline & Usefulness & Ease of Use & Security \\
\hline Usefulness & - & & - \\
Ease of use & 0.005 & 0.721 & - \\
Security & 0.002 & 0.143 & 0.829 \\
Functionality & $<0.001$ &
\end{tabular}

In order to make an appropriate interpretation, the mean values of the evaluation results presented in the Table 4 should be analyzed. It turns out that the highest rated among the groups of features was usefulness (4.35). It was assessed significantly better than the other three groups. In contrast, there were no statistically significant differences between ease of use, security and functionality.

Table 4. Means and standard deviations for the RPA technology features' evaluation.

\begin{tabular}{ccc}
\hline & $M$ & $S D$ \\
\hline Usefulness & 4.35 & 0.67 \\
Ease of use & 4.10 & 0.74 \\
Security & 3.99 & 0.93 \\
Functionality & 3.93 & 0.74 \\
\hline
\end{tabular}

\subsection{The Determinants and Barriers of RPA Technology Adoption}

The respondents also assessed the determinants and barriers of RPA technology adoption identified by the author in the literature by indicating to what extent they agreed with the statements (1-strongly disagree, 5-strongly agree). The next step of the analysis involved checking distributions of the quantitative variables. For this purpose, basic descriptive statistics were calculated along with the Shapiro-Wilk test. The results of the Shapiro-Wilk test are statistically significant for each variable. This means that their distributions are far from the Gaussian curve, but the skewness does not exceed the absolute value of 1 . Therefore, the analyses are based on parametric tests-as long as their other assumptions are met. An exception to this is employee attitude regarding satisfaction. The skewness for this variable does not fall within the conventional limit. The analyses of this variable were confirmed with a nonparametric test. The results of distributions of the quantitative variables and the Shapiro-Wilk test are presented in Table 5. 
Table 5. Basic descriptive statistics along with the results of the Shapiro-Wilk test.




Table 5. Cont.

\begin{tabular}{|c|c|c|c|c|c|c|c|c|c|c|}
\hline Abbr. & Item Description & $\mathbf{M}$ & Me & SD & Sk. & Kurt. & Min & Max & W & $p$ \\
\hline & Problems with ensuring an adequate level of data security [69] & 2.91 & 3.00 & 1.14 & 0.32 & -0.73 & 1.00 & 5.00 & 0.90 & $<0.001$ \\
\hline \multicolumn{11}{|c|}{ Features } \\
\hline & Usefulness & 4.35 & 4.60 & 0.67 & -0.65 & -1.00 & 3.00 & 5.00 & 0.84 & $<0.001$ \\
\hline & Ease of use & 4.10 & 4.33 & 0.74 & -0.28 & -1.29 & 2.83 & 5.00 & 0.89 & $<0.001$ \\
\hline & Security & 3.99 & 4.00 & 0.93 & -0.85 & 0.24 & 1.60 & 5.00 & 0.88 & $<0.001$ \\
\hline & Functionality & 3.93 & 4.00 & 0.74 & -0.13 & -1.16 & 2.71 & 5.00 & 0.92 & $<0.001$ \\
\hline
\end{tabular}


In order to test the relationship between the barriers to decision-making on implementing the RPA technology and the evaluation of this technology, analyses of the Pearson correlation coefficient were performed. The results of the statistical analyses are statistically insignificant because none of the values of the correlation was below the value 0.05 . This means that the barriers to decision-making on implementing the RPA technology at an enterprise are not related to the evaluation of this technology (Table 6).

Table 6. Correlations between the barriers to RPA technology implementation and the RPA technology evaluation.

\begin{tabular}{|c|c|c|c|c|c|}
\hline Barriers & & Usefulness & Ease of Use & Security & Functionality \\
\hline \multirow{2}{*}{ Management reluctance } & Pearson's $r$ & 0.04 & -0.05 & -0.09 & -0.01 \\
\hline & Significance & 0.742 & 0.673 & 0.383 & 0.940 \\
\hline \multirow{2}{*}{ Reluctance of employees, fear of dismissal } & Pearson's $r$ & -0.07 & 0.03 & -0.10 & -0.08 \\
\hline & Significance & 0.496 & 0.753 & 0.373 & 0.473 \\
\hline \multirow{2}{*}{$\begin{array}{l}\text { Frequent changes in processes, large number } \\
\text { of exceptions }\end{array}$} & Pearson's $r$ & -0.02 & -0.12 & -0.09 & -0.09 \\
\hline & Significance & 0.819 & 0.284 & 0.394 & 0.389 \\
\hline \multirow{2}{*}{$\begin{array}{l}\text { Large proportion of paper documents entering } \\
\text { the processes }\end{array}$} & Pearson's $r$ & -0.13 & -0.02 & -0.07 & -0.11 \\
\hline & Significance & 0.220 & 0.861 & 0.525 & 0.312 \\
\hline \multirow{2}{*}{ Nonoptimized and nonstandardized processes } & Pearson's $r$ & 0.10 & 0.10 & 0.18 & 0.17 \\
\hline & Significance & 0.371 & 0.371 & 0.098 & 0.120 \\
\hline \multirow{2}{*}{ Excessive costs of technology implementation } & Pearson's $r$ & 0.13 & 0.05 & 0.16 & 0.15 \\
\hline & Significance & 0.218 & 0.628 & 0.127 & 0.165 \\
\hline \multirow{2}{*}{$\begin{array}{l}\text { Problems with ensuring an adequate level of } \\
\text { data security }\end{array}$} & Pearson's $r$ & -0.06 & -0.02 & 0.08 & 0.00 \\
\hline & Significance & 0.557 & 0.829 & 0.476 & 0.996 \\
\hline
\end{tabular}

The next stage of statistical analyses, again, necessitated the Pearson correlation, which was performed for the relationship between the significance indicated for the determinants of implementing the RPA technology and its evaluation.

From the conducted analyses, it appears that the importance of the determinant "Employees who perform repetitive tasks are inefficient" is positively related to all the RPA technology evaluation features. For ease of use and security, there are moderate relationships; for usefulness, there is a strong relationship; for functionality, there is a weak relationship. The positive nature of these relationships indicates that the more important it is in the implementation of the RPA technology that workers performing repetitive tasks are inefficient, the better the evaluation of the RPA technology.

On the other hand, the importance of the situation in which the developers of the systems implemented in the company no longer work in there covaries negatively with the usefulness of the RPA technology (weak relationship). The greater the importance attributed to this determinant, the weaker the evaluation of the usefulness of the RPA technology. The evaluation of the impact that employees lose time because they are busy rewriting data between systems and do not have time for business development activities correlates positively with all the RPA technology evaluation features. Mostly, these relationships are strong, with the exception of functionality (moderate relationship). The positive type of this relationship indicates that the more important the discussed determinant of implementing the RPA technology is for the respondents, the better is its evaluation.

Furthermore, a positive correlation was found between the importance of the awareness that advanced business process automation is inevitable and the security of the RPA technology (weak correlation). This shows that the more important this awareness is for the respondents, the safer the RPA technology is in their opinion. 
Additionally, the importance of the determinant indicating the ability to maintain processes, preserve business continuity and meet operational objectives is negatively correlated with the security and functionality of the RPA technology (weak relationships). The negative nature of these relationships indicates that the higher the importance of the abovementioned determinant, the weaker the evaluation of the RPA technology in the area of security and functionality. On the other hand, lower operational costs covary positively with the security of the RPA technology (weak correlation). This means that if the respondents consider lower operational costs are more important for the implementation of the RPA technology, the better they evaluate the security aspect of this technology.

Positive and weak relationships were noted for the evaluation of the ease of use of the RPA technology and the following determinants: need for remote working of office workers, staff shortages and difficulties in organizing teamwork. The greater the importance of these determinants, the better the respondents rated the RPA technology in terms of ease of use. In contrast, the importance of the awareness that investing in new and innovative technologies is key to achieving a competitive advantage correlates negatively and moderately with usefulness. What follows is the fact that as the significance of this determinant increases, the usefulness rating of the RPA technology decreases.

High staff turnover and difficulty in recruiting staff with the required competencies are negatively related to both usefulness (weak correlation) and functionality (moderate correlation). The greater the importance attributed by the respondents to staff turnover and difficulty in recruiting staff with the required competencies, the weaker the evaluation of the usefulness and functionality of the RPA technology. Still, the determinant indicating earlier implementation of these solutions covaries negatively with all the RPA technology evaluation features. Mostly, these are moderate correlations, with the exception of security (weak relationship). The negative nature of this relationship indicates that as the importance of this determinant increases, the assessment of the RPA technology decreases.

The remaining correlations were found to be statistically insignificant. The results of all the correlation analyses between the determinants of implementing the RPA technology and its evaluation are presented in Table 7.

Table 7. Correlations between the determinants of RPA technology adoption and its evaluation.

\begin{tabular}{|c|c|c|c|c|c|}
\hline & & Usefulness & Ease of Use & Security & Functionality \\
\hline \multirow{2}{*}{$\begin{array}{c}\text { Employees who perform repetitive tasks are } \\
\text { inefficient }\end{array}$} & Pearson's $r$ & 0.52 & 0.42 & 0.37 & 0.26 \\
\hline & Significance & $<0.001$ & $<0.001$ & $<0.001$ & 0.015 \\
\hline \multirow{2}{*}{$\begin{array}{l}\text { Young employees ("millennials") are not } \\
\text { interested in doing repetitive, tedious jobs }\end{array}$} & Pearson's $r$ & 0.04 & 0.08 & 0.12 & 0.10 \\
\hline & Significance & 0.735 & 0.436 & 0.253 & 0.334 \\
\hline \multirow{2}{*}{$\begin{array}{l}\text { Employees waste time because they are busy } \\
\text { rewriting data between systems }\end{array}$} & Pearson's $r$ & 0.51 & 0.57 & 0.52 & 0.33 \\
\hline & Significance & $<0.001$ & $<0.001$ & $<0.001$ & 0.001 \\
\hline \multirow{2}{*}{$\begin{array}{l}\text { Awareness that advanced automation of } \\
\text { business processes is inevitable }\end{array}$} & Pearson's $r$ & 0.08 & 0.18 & 0.25 & 0.11 \\
\hline & Significance & 0.471 & 0.101 & 0.021 & 0.328 \\
\hline \multirow{2}{*}{$\begin{array}{c}\text { Ability to maintain processes, preserve } \\
\text { business continuity and meet operational } \\
\text { objectives }\end{array}$} & Pearson's $r$ & -0.01 & -0.09 & -0.28 & -0.29 \\
\hline & Significance & 0.959 & 0.410 & 0.009 & 0.007 \\
\hline \multirow{2}{*}{ Extra time for crisis management } & Pearson's $r$ & 0.06 & 0.09 & -0.02 & -0.16 \\
\hline & Significance & 0.570 & 0.414 & 0.864 & 0.143 \\
\hline \multirow{3}{*}{ Lower operating costs } & Pearson's $r$ & 0.14 & 0.12 & 0.21 & 0.04 \\
\hline & Significance & 0.181 & 0.276 & 0.049 & 0.678 \\
\hline & Significance & 0.456 & 0.018 & 0.793 & 0.279 \\
\hline \multirow{2}{*}{ Staff shortages } & Pearson's $r$ & 0.12 & 0.25 & 0.18 & -0.08 \\
\hline & Significance & 0.252 & 0.017 & 0.094 & 0.452 \\
\hline
\end{tabular}


Table 7. Cont.

\begin{tabular}{|c|c|c|c|c|c|}
\hline & & Usefulness & Ease of Use & Security & Functionality \\
\hline \multirow{2}{*}{$\begin{array}{l}\text { No need for employees to contact during } \\
\text { isolation/quarantine }\end{array}$} & Pearson's $r$ & 0.09 & 0.18 & 0.16 & 0.02 \\
\hline & Significance & 0.394 & 0.088 & 0.141 & 0.877 \\
\hline \multirow{2}{*}{$\begin{array}{l}\text { Employee overload due to the increased } \\
\text { number of clients, growing number of } \\
\text { overtime hours }\end{array}$} & Pearson's $r$ & -0.18 & 0.14 & 0.19 & -0.06 \\
\hline & Significance & 0.100 & 0.186 & 0.074 & 0.611 \\
\hline \multirow{2}{*}{$\begin{array}{l}\text { Awareness that investing in new and } \\
\text { innovative technologies is key to achieving a } \\
\text { competitive advantage }\end{array}$} & Pearson's $r$ & -0.30 & 0.16 & -0.06 & -0.08 \\
\hline & Significance & 0.005 & 0.129 & 0.574 & 0.449 \\
\hline \multirow{2}{*}{$\begin{array}{l}\text { High staff turnover and difficulty in recruiting } \\
\text { staff with the required competencies }\end{array}$} & Pearson's $r$ & -0.23 & -0.04 & -0.05 & -0.35 \\
\hline & Significance & 0.030 & 0.725 & 0.611 & $<0.001$ \\
\hline
\end{tabular}

To complete the statistical analyses, linear regression analyses were performed for individual determinants of RPA technology implementation "Employees who perform repetitive tasks are inefficient" and "Employees waste time because they are busy rewriting data between systems". The evaluation of the RPA technology was included as a predictor in the model.

Firstly, the analysis was performed for the statement "Employees who perform repetitive tasks are inefficient". The results of this analysis are statistically significant and explain $43 \%$ of the variance of the explained variable. Usefulness and security (positive relationship) and functionality (negative relationship) proved to be significant predictors. Each of these predictors is strong. It follows that as usefulness increases by one unit, the evaluation of the significance that employees who perform repetitive tasks are inefficient increases by one unit. If security is increased by one unit, the importance of the discussed determinant is higher by 0.91 . On the other hand, as functionality increases by one unit, the importance of this statement is lower by 1.28. The results of the regression analysis are presented in Table 8.

Table 8. Regression coefficients for the RPA technology implementation determinant "Employees performing repetitive tasks are ineffective".

\begin{tabular}{|c|c|c|c|c|c|c|c|c|}
\hline & B & SE & $\beta$ & $t$ & $p$ & $F(4,83)$ & $p$ & $R_{a d} j^{2}$ \\
\hline Const & 0.20 & 0.60 & & 0.33 & 0.746 & \multirow{5}{*}{17.15} & \multirow{5}{*}{$<0.001$} & \multirow{5}{*}{0.43} \\
\hline Usefulness & 1.00 & 0.17 & 0.64 & 5.82 & $<0.001$ & & & \\
\hline Ease of use & 0.18 & 0.15 & 0.13 & 1.15 & 0.255 & & & \\
\hline Security & 0.91 & 0.21 & 0.81 & 4.44 & $<0.001$ & & & \\
\hline Functionality & -1.28 & 0.28 & -0.91 & -4.64 & $<0.001$ & & & \\
\hline
\end{tabular}

For the determinant of implementing the RPA technology "Employees waste time because they are busy rewriting data between systems," the model proved to be adequately suited to the data. Moreover, according to the adjusted coefficient of determination $R^{2}$, it accounts for $63 \%$ of the variance of the explained variable. All predictors significantly predict a change in the value of the analyzed statement. Only functionality turned out to be in a negative relationship with the explained variable; the other predictors are positively related. These are mainly strong predictors, with the exception of ease of use (weak predictor).

This model should be interpreted as follows: as usefulness increases by one unit, the importance of the determinant "Employees waste time because they are busy rewriting data between systems" is greater by 0.85 . If ease of use increases by one unit, the importance of this determinant increases by 0.38 . If security increases by one unit, the importance of this 
determinant increases by 1.22. Conversely, in case of functionality, as this value increases by one unit, the importance of this determinant decreases by 1.57 . The results of this linear regression analysis are presented in Table 9.

Table 9. Regression coefficients for the determinant of RPA technology implementation "Employees waste time because they are busy rewriting data between systems".

\begin{tabular}{ccccccccc}
\hline & B & SE & $\boldsymbol{\beta}$ & $\boldsymbol{t}$ & $\boldsymbol{p}$ & $\boldsymbol{F ( 4 , 8 3 )}$ & $\boldsymbol{p}$ & $\boldsymbol{R}_{a d j^{2}}$ \\
\hline Const & 0.08 & 0.47 & & 0.17 & 0.868 & & & \\
Usefulness & 0.85 & 0.14 & 0.56 & 6.25 & $<0.001$ & & & \\
Ease of use & 0.38 & 0.12 & 0.28 & 3.11 & 0.003 & 37.59 & $<0.001$ & 0.63 \\
Security & 1.22 & 0.16 & 1.11 & 7.54 & $<0.001$ & & & \\
Functionality & -1.57 & 0.22 & -1.13 & -7.19 & $<0.001$ & & & \\
\hline
\end{tabular}

\section{Conclusions}

\subsection{Research Contribution}

Since the outbreak of the COVID-19 pandemic, the processes of digital transformation have significantly accelerated and have become the undisputed leaders of all the initiatives undertaken by enterprises, both those that have for a long time been implementing initiatives related to digitization and those that only transformed their activities in the areas of internal operations and work transformation as a result of the pandemic.

The study contributes to scientific knowledge and has practical implications for process automation decision-makers concerned with the adoption of the Robotic Process Automation technology. All the more important is the fact that Kregel supports the claim that RPA is now a mature technology with a prospective further growth of adoption [61].

The result of the research is the diagnosis of the impact of the pandemic on companies' processes and the identification of the fundamental technology features influencing the adoption of Robotic Process Automation by Polish service companies. Sixty percent of the respondents indicated that robotization tools allowed maintaining the continuity of business processes. Nearly half of the surveyed respondents claimed that thanks to the use of business process robotization tools, they were able to handle more orders or transactions.

The features related to the usefulness of the RPA technology largely determine decisions of enterprises to adopt such solutions. The highest scores were assigned to the following features of software robots: E1-Robots replace employees in routine activities, leaving them with creative and competent activities and handling of exceptions, U4-Robots make it possible to achieve economic benefits, U5-Robots optimize the labor costs of back office employees and increase the efficiency of the services provided, $\mathrm{U} 2$ - Robot-assisted workers can handle more processes, so they are more productive and commit less mistakes. The lowest levels of importance (below the average value) were given to the following features of software robots: E5-Robots can be implemented quickly, E3-Robots do not require the use of additional integration technologies (e.g., API, BPM) and F4-Robots give the possibility of a smooth transition to any solutions from other vendors.

The most frequently indicated barriers to technology implementation were related to nonoptimized, non-standardized and non-digitized processes with a large number of exceptions.

\subsection{Research Implications}

The obtained results of this study can help process automation decision-makers to understand the potential drivers of and barriers to the adoption of software robots by enterprises and may be an important determinant for companies' managers to implement such solutions. However, implementing RPA represents a challenge, and organizations must learn to manage RPA adoption to achieve the best results.

In the likely future, organizations may continue to use business process automation solutions, partly as business continuity enablers in case of similar crises but mainly to 
relieve employees of repetitive [69], time-consuming, simple tasks and direct their potential to more ambitious tasks, fostering the development of the company, increasing its competitiveness and the quality of services. Software robots will work side-by-side with humans, enabling people to focus on tasks where creativity and social skills are needed. The perception of the role of human resources must thus be reformulated [68], new roles in business processes must be indicated [34]. It seems to be a very essential issue in the context of the future human-robot interaction.

The paper aimed to identify the most significant features in terms of perceived usefulness, ease of use, security and functionality that influence the adoption of the RPA technology by Polish service enterprises during the COVID-19 pandemic. Such information could be of practical value for managers not only during the pandemic, but also in case of any unprecedented crisis situations as well as in the face of an increasingly rapid digital transformation.

During the COVID-19 crisis, business continuity and productivity have deteriorated significantly. Technology is playing a vital role in tackling the pandemic. RPA will not be a nirvana solution fixing everything in the current situation, but can help to ensure that the processes will have the capability to operate critical business functions during emergency events and support access and interfaces with key tools and applications. In the absence of on-site interaction and communication, RPA can also be used to support employees with questions relating to internal processes. One of the most important challenges for companies is to identify the appropriate processes suitable for automation and robotization with the use of the RPA technology to avoid inefficiency and failure. Therefore, it is necessary to diagnose the potential for the robotization of processes at an enterprise before the decision to implement the RPA technology is made. There is no justification for robotizing business processes that are non-standardized, non-optimized, non-digitized, frequently changed and have many exceptions.

\subsection{Research Limitations}

As every research, this analysis also has its limitations. First of all, this study is limited to RPA as one particular area of automation. That means that the findings might not be completely transferrable to the general discussion of the effects of automation, but the author believes that some arguments might be transferrable by means of logical reasoning. Another limitation is related to the sample, which only involved representatives from Polish service enterprises. The research should therefore be extended to take into account responses of representatives from other sectors. As this survey is only national in nature, comparative research approaches in different countries would further increase the understanding of the phenomena under study. The key findings discussed in this study can be used as research propositions or hypotheses for further studies.

\subsection{Further Research}

Within the digital transformation which is continuously progressing, Robotic Process Automation is drawing much corporate attention. However, while RPA is a popular topic in the corporate world, the academic research lacks a theoretical and synoptic analysis of RPA. Being a niche area of information technology, the literature on RPA is scant [62]. Further investigations should involve a comprehensive assessment of this technology, identification of roadmaps for effective adoption and reveal additional determinants as well as factors influencing the adoption of the RPA technology. Thus, further research should be more profound with the aim to propose and test a framework from the technology-organizationenvironment (TOE) theory to explain SMEs' adoption of the RPA technology. Authors may also analyze the development of software robots' data-related, integration-related and process-related functionalities. Further research should also include the identification of employees' attitudes towards software robots and perceived changes that RPA has on their job characteristics. 
Funding: The publication of the article for 11th International Conference on Engineering, Project, and Production Management-EPPM2021 was financed in the framework of the contract no. DNK/SN/465770/2020 by the Ministry of Science and Higher Education within the "Excellent Science" programme.

Conflicts of Interest: The author declares having no conflict of interest.

\section{References}

1. Atilgan, O. Covid-19 and crisis management. In COVID-19 and New Business Ecosystem; Gazi Publishing: Ankara, Turkey, 2020; pp. 141-153.

2. Margherita, M.; Heikkila, M. Business Continuity in the COVID-19. Emergency: A Framework of Actions Undertaken by World-Leading Companies. Bus. Horiz. 2021. [CrossRef]

3. Păunescu, C.; Argatu, R. Critical functions in ensuring effective business continuity management. Evidence from Romanian companies. J. Bus. Econ. Manag. 2020, 21, 497-520. [CrossRef]

4. Shen, Y.; Guo, D.; Long, F.; Mateos, L.A.; Ding, H.; Xiu, Z.; Hellman, R.B.; King, A.; Chen, S.; Tan, C.H. Robots Under COVID-19 Pandemic: A Comprehensive Survey 2021. IEEE Access 2021, 9, 1590-1615. [CrossRef]

5. Mbunge, E.; Akinnuwesi, B.; Fashoto, S.G.; Metfula, A.S.; Mashwama, P. A critical review of emerging technologies for tackling COVID-19 pandemic. Hum. Behav. Emerg. Technol. 2021, 3, 25-39. [CrossRef] [PubMed]

6. Bullock, J.; Luccioni, A.; Pham, K.H.; Sin Nga Lam, C.; Luengo-Oroz, M. Mapping the Landscape of Artificial Intelligence Applications against COVID-19. J. Artif. Intell. Res. 2020, 69, 807-845. [CrossRef]

7. Javaid, M.; Haleem, A.; Vaishya, R.; Bahl, S.; Suman, R.; Vaish, A. Industry 4.0 technologies and their applications in fighting COVID-19 pandemic. Diabetes Metab. Syndr. Clin. Res. Rev. 2020, 14, 419-422. [CrossRef]

8. Nadikattu, R.R. Information Technologies: Rebooting the World Activities during COVID-19. SSRN Electron. J. 2020. [CrossRef]

9. Agarwal, S.; Punna, N.S.; Sonbhadraa, S.K.; Tanveerb, M.; Nagabhushana, P.; Soundra Pandianc, K.K.; Saxenad, P. Unleashing the power of disruptive and emerging technologies amid COVID-19. arXiv 2020, arXiv:2005.11507.

10. Nah, F.F.N.; Siau, K. Covid-19 pandemic-Role of technology in transforming business to the new normal. In Lecture Notes in Computer Science; Springer: Cham, Switzerland, 2020; pp. 585-600.

11. Bogue, R. Robots in a contagious world. Ind. Robot 2020, 47, 642-673. [CrossRef]

12. Khaleghi, A.; Mohammadi, M.R.; Jahromi, G.P.; Zarafshan, H. New ways to manage pandemics: Using technologies in the era of COVID-19, a narrative review. Iran J. Psychiatry 2020, 15, 236-242. [CrossRef]

13. Wang, X.V.; Wang, L. A literature survey of the robotic technologies during the COVID-19 pandemic. J. Manuf. Syst. 2021 [CrossRef]

14. Van der Aalst, W.M.P.; Bichler, M.; Heinzl, M. Robotic Process Automation. Bus. Inf. Syst. Eng. 2018, 60, 269-272. [CrossRef]

15. Geyer-Klingeberg, J.; Nakladal, J.; Baldauf, F.; Fabian, V. Process Mining and Robotic Process Automation: A Perfect Match. In Proceedings of the 6th International Conference on Business Process Management (BPM), Sydney, NSW, Australia, 9-14 September 2018.

16. Siderska, J. Robotic Process Automation-A Driver of Digitial Transformation? Eng. Manag. Prod. Serv. 2020, 12, $21-31$.

17. Madakam, S.; Holmukhe, R.M.; Jaiswal, D.K. The future digital work force: Robotic Process Automation (RPA). J. Inf. Syst. Technol. Manag. 2019, 16, 1-14. [CrossRef]

18. Santos, F.; Pereira, R.; Vasconcelos, J.B. Toward Robotic Process Automation implementation. Bus. Process Manag. J. 2018, 3 , $405-420$.

19. Kozłowska, J. Servitization of manufacturing: Survey in the Polish machinery sector. Eng. Manag. Prod. Serv. 2020, 12, 20-33.

20. Mendling, J.; Decker, G.; Hull, R.; Reijers, H.A.; Weber, I. How do Machine Learning, Robotic Process Automation and Blockchains Affect the Human Factor in Business Process Management? Commun. Assoc. Inf. Syst. 2018, 43, 297-320. [CrossRef]

21. IEEE Corporate Advisory Group. IEEE Guide for Terms and Concepts in Intelligent Process Automation; IEEE: Piscataway, NJ, USA, 2017.

22. Miniati, R.; Dori, F.; Cecconi, G.; Gusinu, R.; Niccolini, F.; Gentili, B.G. HTA decision support system for sustainable business continuity management in hospitals. The case of surgical activity at the Univesity Hospital in Florence. Technol. Health Care 2013, 21, 49-61. [CrossRef]

23. Houy, C.; Reiter, M.; Fettke, P.; Loos, P.; Hoesch-Klohe, K.; Ghose, A. Advancing Business Process Technology for Humanity: Opportunities and Challenges of Green BPM for Sustainable Business Activities. In Green Business Process Management; vom Brocke, J., Seidel, S., Recker, J., Eds.; Springer: Berlin/Heidelberg, Germany, 2012.

24. Geissdoerfer, M.; Bocken, N.M.P.; Hultink, E.J. Design thinking to enhance the sustainable business modelling process-A workshop based on a value mapping process. J. Clean. Prod. 2016, 135, 1218-1232. [CrossRef]

25. Opitz, N.; Krüp, H.; Kolbe, L.M. Environmental sustainable business process management—Developing a green BPM readiness model. In Proceedings of the PACIS 2014 Proceedings, Chengdu, China, 24-28 June 2014; p. 12.

26. Kucia, M.; Hajduk, G.; Mazurek, G.; Kotula, N. The Implementation of New Technologies in Customer Value Management-A Sustainable Development Perspective. Sustainability 2021, 13, 469. [CrossRef]

27. Doyle, R.; Conboy, K. The role of IS in the covid-19 pandemic: A liquid-modern perspective. Int. J. Inf. Manag. 2020, 55, 102184. [CrossRef] 
28. Pan, S.L.; Zhang, S. From fighting COVID-19 pandemic to tackling sustainable development goals: An opportunity for responsible information systems research. Int. J. Inf. Manag. 2020, 55, 102196. [CrossRef]

29. Fletcher, G.; Griffiths, M. Digital transformation during a lockdown. Int. J. Inf. Manag. 2020, 55, 102185. [CrossRef]

30. Bunker, D. Who do you trust? The digital destruction of shared situational awareness and the COVID-19 infodemic. Int. J. Inf. Manag. 2020, 55, 102201. [CrossRef]

31. Ejdys, J.; Gudanowska, A.; Halicka, K.; Kononiuk, A.; Magruk, A.; Nazarko, J.; Nazarko, Ł.; Szpilko, D.; Widelska, U. Foresight in Higher Education Institutions: Evidence from Poland. Foresight STI Gov. 2018, 13, 77-89. [CrossRef]

32. Hallikainen, P.; Bekkhus, R.; Pan, S.L. How Opuscapita used internal RPA capabilities to offer services to clients. MIS Q. Exec. 2018, 17, 41-52.

33. Khramov, D. Robotic and Machine Learning: How to Help Support to Process Customer Tickets More Effectively; Metropolia University of Applied Sciences: Helsinki, Finland, 2018.

34. Lacity, M.; Willcocks, L.P.; Craig, A. Service Automation: Cognitive Virtual Agents at SEB Bank. 2017. Available online: http:/ / www.umsl.edu/ \{\}lacitym/LSEOUWP1701.pdf (accessed on 11 January 2021).

35. Lacity, M.; Willcocks, L.P.; Craig, A. Robotic Process Automation at Telefonica O2. MIS Q. Exec. 2015, 15, 1-19.

36. Herbert, I.P. How Students Can Combine Earning with Learning through Flexible Business Process Sourcing: A Proposition; Loughborough University: Loughborough, UK, 2016.

37. Willcocks, L.; Lacity, M.; Craig, A. Robotic process automation: Strategic transformation lever for global business services? J. Inf. Technol. 2017, 7, 17-28. [CrossRef]

38. Holder, C.; Khurana, V.; Harrison, F.; Jacobs, L. Robotics and law: Key legal and regulatory implications of the robotics age. Comput. Law Secur. Rev. 2016, 32, 383-402. [CrossRef]

39. Jurczuk, A. Wieloaspektowa Identyfikacja i Typologia Źródeł Niespójności Procesów Biznesowych; Oficyna Wydawnicza Politechniki Białostockiej: Białystok, Poland, 2019. (In Polish)

40. Bhatt, M. Ensure Business Continuity with RPA. Available online: https://nuummite.consulting/ensure-business-continuity/ (accessed on 2 April 2021).

41. Hofmann, P.; Samp, C.; Urbach, N. Robotic process automation. In Electronic Markets; Springer, IM University of St. Gallen: St. Gallen, Switzerland, 2020; Volume 30, pp. 99-106.

42. Enriquez, J.G.; Jimenez-Ramirez, A.; Dominguez-Mayo, F.J.; Garcia-Garcia, J.A. Robotic Process Automation: A Scientific and Industrial Systematic Mapping Study. IEEE Access 2020, 8, 39113-39129. [CrossRef]

43. Schlegel, D.; Kraus, P. Robotic Process Automation as an emerging career opportunity: An analysis of required qualifications and skills. In Proceedings of the 13th Annual Conference of the EuroMed Academy of Business, Palermo, Italy, 16-18 September 2020; pp. 1083-1097.

44. Ivančić, L.; Vugec, D.S.; Vuksic, V.B. Robotic Process Automation: Systematic Literature Review. In Business Process Management: Blockchain and Central and Eastern Europe Forum; Springer: Cham, Switzerland, 2020; pp. 280-295.

45. Anagoste, S. Robotic Automation Process-The next major revolution in terms of back office operations improvement. In Proceedings of the 11th International Conference on Business Excellence, Bucharest, Romania, 30-31 March 2017; pp. 676-686.

46. Syed, R.; Suriadi, S.; Adams, M.; Bandara, W.; Leemans, S.J.; Ouyang, C.; Ter Hofstede, I.A.H.; Weerd, V.D.; Wynn, M.T.; Reijers, H.A. Robotic process automation: Contemporary themes and challenges. Comput. Ind. 2020, 115, 103162. [CrossRef]

47. Pinzaru, F.; Zbuchea, A.; Anghel, L. The Impact of The COVID-19 Pandemic on Business. A Preliminary Overview, Crisis and Risk Management. Strategica 2020, 721-730. Available online: https:/ / www.researchgate.net/profile/Simona-Stanescu-2/ publication/345945063_Strategica_2020_PROMOTING_SOCIAL_RESILIENCE_IN_RURAL_AREAS_THROUGH_SOCIAL_ ECONOMY_IN_TIME_OF_THE_COVID-19_PANDEMIC/links/5fb2a1f292851cf24cd7ff9f/Strategica-2020-PROMOTINGSOCIAL-RESILIENCE-IN-RURAL-AREAS-THROUGH-SOCIAL-ECONOMY-IN-TIME-OF-THE-COVID-19-PANDEMIC. pdf\#page $=721$ (accessed on 17 July 2021).

48. Lasso-Rodriguez, G.; Winkler, K. Hyperautomation to fulfil jobs rather than executing tasks: The BPM manager robot vs. human case. Rom. J. Inf. Technol. Autom. Control 2020, 30, 7-22. [CrossRef]

49. Arindam, D. Robotic process automation: Assessment of the technology for transformation of business processes. Int. J. Bus. Process Integr. Manag. 2019, 9, 220-230.

50. Hindel, J.; Cabrera, L.; Stierle, M. Robotic Process Automation: Hype or Hope? In Proceedings of the 15th International Conference on Wirtschaftsinformatik, Potsdam, Germany, 9-11 March 2020.

51. Bourgouin, A.; Leshob, A.; Renard, L. Towards a Process Analysis Approach to Adopt Robotic Process Automation. In Proceedings of the 2018 IEEE 15th International Conference on e-Business Engineering (ICEBE), Xi'an, China, 12-14 December 2018.

52. Asatiani, A.; Penttinen, E. Turning Robotic Process Automation into commercial success—Case OpusCapita. J. Inf. Technol. 2016, 6, 67-74. [CrossRef]

53. Fung, H.P. Criteria, Use Cases and Effects of Information Technology Process Automation (ITPA). Adv. Robot. Autom. 2013, 3 , 2588999.

54. Vom Brocke, J.; Maaß, W.; Buxmann, P.; Maedche, A.; Leimeister, J.M.; Pecht, G. Future Work and Enterprise Systems. Bus. Inf. Syst. Eng. 2018, 60, 357-366. [CrossRef]

55. Dialani, P. 4 Robotic Process Automation Trends for 2020. 2019. Analytics Insight. Available online: https://www.analyticsinsight. net /4-robotic-process-automation-trends-for-2020/ (accessed on 4 October 2020). 
56. Ng, K.K.H.; Chen, C.-H.; Lee, C.K.M.; Jiao, J.; Yang, Z.-X. A systematic literature review on intelligent automation: Aligning concepts from theory, practice, and future perspectives. Adv. Eng. Inform. 2021, 47, 101246. [CrossRef]

57. Yoon, S. A study on the transformation of accounting based on new technologies: Evidence from Korea. Sustainability 2020, 12, 8669. [CrossRef]

58. Wewerka, J.; Dax, S.; Reichert, M. A User Acceptance Model for Robotic Process Automation. In Proceedings of the IEEE 24th International Enterprise Distributed Object Computing Conference (EDOC), Eindhoven, The Netherlands, 5-8 October 2020; pp. 11-19.

59. Wewerka, J.; Reichert, M. Towards Quantifying the Effects of Robotic Process Automation. In Proceedings of the IEEE 24th International Enterprise Distributed Object Computing Workshop (EDOC), Eindhoven, The Netherlands, 5-8 October 2020; pp. $1-9$.

60. Junteen, K. Influence of Contextual Factors on the Adoption Process of Robotic Process Automation (RPA); Case Study at Stora Enso Finance Delivery: Uppsala, Sweden, 2018.

61. Vu, H.T.; Lim, J. Effects of country and individual factors on public acceptance of artificial intelligence and robotics technologies: A multilevel SEM analysis of 28-country survey data. Behav. Inf. Technol. 2021. [CrossRef]

62. Aldossari, M.; Zin, A.M. The use of automation and robotic innovations in the transformational companies: Systematic literature review. J. Theor. Appl. Inf. Technol. 2019, 97, 3661-3690.

63. Kumar, A.; Ayedee, N. Technology Adoption: A Solution for SMEs to Overcome Problems during COVID-19. Forthcom. Acad. Mark. Stud. J. 2021, 25, 3745814.

64. Reddy Naveen, K.P.; Harichandana, U.; Alekhya, T.; Rajesh, S.M. A Study of Robotic Process Automation among Artificial Intelligence. Int. J. Sci. Res. Publ. 2019, 9, 392-397. [CrossRef]

65. Jovanovic, S.Z.; Durić, J.S.; Sibalicja, T.V. Process Automation: Overview and opportunities. Int. J. Adv. Qual. 2018, 46, 3-4.

66. Anagoste, S. Robotic Automation Process-The operating system for the digital enterprise. In Proceedings of the 12th International Conference on Business, Bali, Indonesia, 7-8 November 2018.

67. Starting with RPA: The Diagnosis and Treatment of Technology Debt in Healthcare. Available online: https://www.westmonroe. $\mathrm{com} /$ perspectives / point-of-view / starting-with-rpa-the-diagnosis-and-treatment-of-technology-debt-in-healthcare (accessed on 2 February 2020).

68. Romão, M.; Costa, J.; Costa, C.J. Robotic Process Automation: A Case Study in the Banking Industry. In Proceedings of the 14th Iberian Conference on Information Systems and Technologies (CISTI), Coimbra, Portugal, 19-22 June 2019.

69. Gudanowska, A.; Kononiuk, A.; Siderska, J.; Dębkowska, K. (Eds.) Uwarunkowania Ucyfrowienia Procesów Produkcji i Wzrostu Kompetencji Cyfrowych Społeczeństwa; Oficyna Wydawnicza Politechniki Białostockiej: Białystok, Poland, 2020. (In Polish) 